\title{
The discipline of enterprise engineering
}

\author{
Jan L.G. Dietz* \\ Delft University of Technology, \\ P.O. Box 5015, 2600GA, Delft, The Netherlands \\ E-mail: j.l.g.dietz@tudelft.nl \\ *Corresponding author
}

\section{Jan A.P. Hoogervorst}

Antwerp Management School, Sint-Jacobsmarkt 9-13, BE-2000 Antwerpen, Belgium

E-mail: jan.hoogervorst@ams.ac.be

\section{Antonia Albani, David Aveiro, Eduard Babkin, Joseph Barjis, Artur Caetano, Philip Huysmans, Junichi lijima, Steven J.H. van Kervel, Hans Mulder, Martin Op 't Land, Henderik A. Proper, Jorge Sanz, Linda Terlouw, José Tribolet, Jan Verelst and Robert Winter ${ }^{1}$}

\begin{abstract}
A century ago, Taylor published a landmark in the organisational sciences: his Principles of Scientific Management. Many researchers have elaborated on Taylor's principles, or have been influenced otherwise. The authors of the current paper evaluate a century of enterprise development, and conclude that a paradigm shift is needed for dealing adequately with the challenges that modern enterprises face. Three generic goals are identified. The first one, intellectual manageability, is the basis for mastering complexity; current approaches fall short in assisting professionals to master the complexity of enterprises and enterprise changes. The second goal, organisational concinnity, is conditional for making strategic initiatives operational; current approaches do not, or inadequately, address this objective. The third goal, social devotion, is the basis for achieving employee empowerment as well as knowledgeable management and governance; modern employees are highly educated knowledge workers; yet, the mindset of managers has not evolved accordingly. The emerging discipline of Enterprise Engineering, as conceived by the authors, is considered to be a suitable vehicle for achieving these goals. It does so by providing new, powerful theories and effective methodologies. A theoretical framework is presented for positioning the theories, goals, and fundamentals of enterprise engineering in four classes: philosophical, ontological, ideological and technological.
\end{abstract}

Keywords: scientific management; enterprise engineering; enterprise ontology; enterprise architecture; enterprise design; enterprise governance; enterprise management. 
Reference to this paper should be made as follows: Dietz, J.L.G., Hoogervorst, J.A.P., Albani, A., Aveiro, D., Babkin, E., Barjis, J., Caetano, A., Huysmans, P., Iijima, J., van Kervel, S.J.H., Mulder, H., Op 't Land, M., Proper, H.A., Sanz, J., Terlouw, L., Tribolet, J., Verelst, J. and Winter, R. (2013) 'The discipline of enterprise engineering', Int. J. Organisational Design and Engineering, Vol. 3, No. 1, pp.86-114.

Biographical notes: Jan L.G. Dietz is Emeritus Professor in Information Systems Design and a Professor in Enterprise Engineering at Delft University of Technology. He received his Doctoral degree in Computer Science from Eindhoven University of Technology. He has published over 250 scientific and professional articles and books. His current research interests are in the theory and practice of enterprise engineering. He is the spiritual father of the DEMO methodology, founder and Honorary Chairman of the Enterprise Engineering Institute, founder and Chairman of the international research network CIAO!, the Director of Sapio Enterprise Engineering, and the Editor-in-Chief of the Springer book series on enterprise engineering.

Jan A.P. Hoogervorst studied electrical engineering at the Delft University of Technology, and obtained his PhD in Work and Organisational Psychology from the Amsterdam Free University. At KLM Royal Dutch Airlines, he held various executive management positions. This extensive management expertise forms the inspiration for teaching and research, enterprise governance and enterprise engineering, aiming to provide an overarching multidisciplinary perspective to integrate and unify insights from the traditional organisational sciences into an overall enterprise design perspective. He is a (part-time) Professor at the Antwerp Management School. His thoughts are reflected in the book Enterprise Governance and Enterprise Engineering.

Antonia Albani holds Master and $\mathrm{PhD}$ degrees in Computer Science. She is a Senior Researcher at the University of St. Gallen, Switzerland. Previously, she was an Assistant Professor at the Delft University of Technology, The Netherlands. She is a cofounder of the research network Cooperation \& Interoperability - Architecture \& Ontology (CIAO!) (http://www.ciaonetwork. org) and member of the CIAO! executive board. She worked in IT consulting and was CEO and cofounder of an internet start-up in the area of business process outsourcing. Her main research interests are on service innovation and service engineering.

David Aveiro is an Invited Assistant Professor at the Exact Sciences and Engineering Centre of the University of Madeira in Portugal. His research interests include organisational engineering and organisational change. His teaching interests include organisational engineering, database management systems and decision support systems. He received his MSc degree and his $\mathrm{PhD}$ in Computer Science and Information Systems Engineering from the Instituto Superior Técnico of the Technical University of Lisbon.

Eduard Babkin is a Professor at the National Research University 'Higher School of Economics' (Russia). Currently, he is the Head of the Department of Information Systems and Technologies at that university, and both an associate member of LITIS laboratory at the National Institute of Applied Sciences (Rouen, France). He has ten years of practical experience in R\&D, architecting and project management of complex distributed systems for large international telecommunication companies. In 2007, he obtained his $\mathrm{PhD}$ in Computer Science at the National Institute of Applied Sciences. His scientific interests include enterprise engineering, multi-agent systems, knowledge representation and processing. 
Joseph Barjis is an Associate Professor at Delft University of Technology. His research includes enterprise engineering, modelling and simulation, and systems engineering. He has published in journals such as Enterprise Information Systems, Information Systems Frontiers, SIMULATION Transaction of The Society for Modeling and Simulation International, and Journal of Enterprise Transformation. His research resulted in 13 edited conference books, 14 book chapters, 23 journal articles and editorials, Guest Editor of 10 special issues, and over 70 papers in refereed conferences. He has been an invited speaker to international forums, general chair of international workshops and serves in the editorial board of journals.

Artur Caetano is an Assistant Professor in Information Systems at the Instituto Superior Tecnico, Technical University of Lisbon, Portugal, Researcher at the Information Systems Group, INESC-ID, and Unit Coordinator of the Centre for Organizational Design \& Engineering, INESC-INOV. He has published over 50 articles related to enterprise architecture, business process modelling, service-oriented architectures and object-oriented modelling. He has participated in European projects related to these topics and regularly serves the editorial board of journals and the programme committee of conferences related to the theme of enterprise engineering. He is a member of ACM, IEEE and INCOSE.

Philip Huysmans is a Post-doctoral Researcher in Management Information Systems at the University of Antwerp (BE) and a member of the Normalized Systems Institute. His main research interests are in normalised systems, enterprise engineering and enterprise architecture. In addition to being a speaker at international conferences and publishing in international journals, he teaches courses on software analysis and design, enterprise architecture and DEMO at the undergraduate and postgraduate level. He is also a board member of the Enterprise Engineering Institute.

Junichi Iijima is a Professor in Information Systems at Tokyo Institute of Technology (TokyoTech, JPN). He is the Dean of the Graduate School of Decision Science and Technology of TokyoTech in 2011-2012. He has published over 200 scientific and professional articles and books. His current research interests are in the theory and practice of enterprise engineering. $\mathrm{He}$ is a former President of JASMIN (Japan Association for Management Information) that is the largest association on information systems in Japan, and the current Vice President of the Society of Business Process Management.

Steven J.H. van Kervel is currently the Director of Formetis BV, The Netherlands (http://www.formetis.nl). His current research interest is in enterprise engineering and model-driven information systems engineering, based on the DEMO methodology. His previous research and development includes analogue and digital electronics, medical ultrasound technology, and CDROM technology. He has also developed an object-oriented environment for low-structured document information systems. He received his MSc in Electrical Engineering from the Eindhoven University of Technology and his $\mathrm{PhD}$ in Software Engineering from the Delft University of Technology.

Hans Mulder is an Executive Professor of Enterprise Engineering at Antwerp Management School (AMS), TUDelft TopTech, Dirksen University of Applied Sciences and Lecturer at the Police Academy of the Netherlands. He is the Chairman of NOVI University of Applied Sciences and the platform ICT-Hogescholen in which seven universities of applied sciences collaborate in the innovation of ICT exams. He received his $\mathrm{PhD}$ degree at Delft University of Technology (Information Systems Department). He founded the Venture 
Informatisering Adviesgroep N.V. (VIAgroep) and has several positions in IT industry. He is the founder of Meeting-lab.nl, Advisor of Inventive Academy, the Chief Technology Officer of B-Able and the Chairman of the supervisory board of Finalist and Five4U.

Martin Op 't Land works as a Principal Consultant and Certified Enterprise Architect at Capgemini with 28 years of experience in coherently (re)shaping organisation and information of extended enterprises in splits, mergers and alliances. He combines this with research and education as a Professor of Enterprise Engineering at the University of Antwerp Management School. He developed an evidence-based accelerator for effective organisation splitting and allying $(\mathrm{PhD}, 2008)$ and wrote Enterprise Architecture - Creating Value by Informed Governance (Springer, 2009). He is a board member of the Enterprise Engineering Institute, participant in the international research network CIAO! and Editor of the Springer Enterprise Engineering Series.

Henderik A. Proper is a Professor of Information Systems at the Radboud University Nijmegen, the Netherlands. $\mathrm{He}$ is one of the co-initiators of the development of the ArchiMate language for enterprise architecture. He is currently a Senior Research Manager at Public Research Centre - Henri Tudor in Luxembourg, where he leads the research programme on enterprise engineering. He has co-authored two books on enterprise architecture, and provided substantial contributions to two other books on this topic. He is also the Editor-in-Chief of a book series on enterprise engineering, published by Springer. His home on the web can be found at http://www.erikproper.eu.

Jorge Sanz has more than 20 years of research and practical experience in business transformation and the interplay with technical areas of information sciences and communication technologies. He works for IBM Research in San Jose, California. He was the Director for Innovative Technologies in IBM World Trade. He actively consults for European, North American and Latin American companies. He was a Full Professor in the USA and the President of a business and economics school in Latin America. He has more than 130 published papers and several books. He is a Fellow of the IEEE Society.

Linda Terlouw received both her MSc in Computer Science and Msc in Business Information Technology from the University of Twente. She started her career working for IBM. In 2005, she joined the SOA Consulting Group of Ordina, a large IT services provider in the Netherlands. In the same year, she went back to the academia (part-time) to pursue her $\mathrm{PhD}$ in Computer Science at the Delft University of Technology. The focus of this research was the specification of services working from formal organisational models. The research was part of the CIAO! Program. In 2009, she started the company ICRIS

José Tribolet is a Full Professor of Information Systems at the Instituto Superior Técnico (IST), Portugal. His main academic interests are in enterprise architecture, engineering, governance and transformation. Since 2000 , he has supervised nine $\mathrm{PhD}$ students. He has published over 200 scientific papers and professional articles. He plays a leading role in the CIAO! Consortium and is Co-editor of the Springer Enterprise Engineering book series. He maintains an active professional profile. He plays a leading advisory role in GPERRTIC, a national strategic programme to rationalise and improve the information systems and ITC infrastructures of the Portuguese public administration. 
Jan Verelst received his PhD in Management Information Systems from the Faculty of Applied Economics of the University of Antwerp, Belgium, in 1999. His research interests focus on methodologies for the development of normalised systems. He is the Chairman of the Department of Management Information Systems at the University of Antwerp, where he teaches courses on methodologies concerning analysis and design of information systems. He is also a Professor at the Antwerp Management School, where he lectures in the executive master in enterprise IT architecture.

Robert Winter is Tenured Chair of Business and Information Systems Engineering at the University of St. Gallen (HSG) and the Director of HSG's Institute of Information Management. After receiving his Master degrees in Business Administration and Business Education as well as his Doctorate in Social Sciences from Goethe University, Frankfurt, and eleven years as a Researcher and Deputy Chair, he joined HSG in 1996. His research interests include situational method engineering, enterprise architecture management, transformation management and corporate controlling systems. He is the Vice Editor-in-Chief of Business \& Information Systems Engineering as well as member of the editorial boards of EJIS, ISeB and EMISA.

\section{Introduction}

A century ago, Taylor (1911) published his famous paper, titled The Principles of Scientific Management. In the present paper, we take the anniversary of Taylor's seminal paper as an opportunity to look back at a century of theory and practice in enterprise ${ }^{2}$ development in general, to assess the current state, and to propose a radical new way of addressing current problems, under the name of 'enterprise engineering', pursuing three generic goals: intellectual manageability, organisational concinnity, and social devotion.

Up to now, the field of enterprise engineering, as we conceive it, does not include the study of the business of an enterprise, thus its role in the society, or its market. Such sociological and economic studies must certainly be included in the future.

\subsection{Critiques on scientific management}

Over the years, scientific management has contributed to significant increases in the productivity of enterprises. Typical characteristics of the scientific management approach are the minute division of labour in simple, repetitive tasks, and the clear separation between thinking and doing. Workers are instrumentally viewed as parts of the enterprise 'machine'. According to Taylor, a man fit to do the manual work is however unfit to understand the science of doing his work. Hence, managerial control is essential. Taylor's perspective is supported by contemporary writers, such as Fayol (1990) and Weber (1924).

Taylor's approach has been heavily criticised. Basically, two kinds of criticisms can be identified. The first one regards ethical considerations concerning the deployment of human capacities in enterprises. Various researchers have argued that the principles of scientific management lead to worker deprivation and alienation, and to destroying the meaning of work itself (Fromm, 1942, 1955; Mintzberg, 1989). These phenomena were already visible a few years after Taylor published his paper, when his principles were 
practiced in Ford's car manufacturing: workers' jobs were depleted of skill, autonomy and control, leading to extreme worker turnover rates (Hounshell, 1984). Contenders of Taylor thus argue the importance of employee development, self-initiated behaviour, and self-control.

Considerations concerning the effectiveness and efficiency of enterprises constitute the second kind of criticism. Essentially, the critique boils down to two aspects. First, the notion that proper attention to employees as a social group can significantly enhance enterprise effectiveness and efficiency, as for example, evidenced by the classical Hawthorne studies (Mayo, 1949). Noteworthy within this perspective is the 'socio-technical approach' - introduced by the seminal work of Trist and Bamforth (1951) - that argues the mutual relationship between the social and technological 'system' of an enterprise. Hence, these systems must be jointly designed since they can mutually support each other to enhance enterprise effectiveness and efficiency. Second, it is argued that the mere instrumental view on employees - workers as labour resources undervalues human cognitive and social capacities. This shift in focus is evidenced by landmark publications like McGregor (1960), Likert (1965) and Katz and Kahn (1978). The shift in focus considers employees, and their involvement and participation, as the critical core for enterprise success. Rightly so, Drucker (1985) considers aspects of human behaviour as the primary concerns of management science. As Drucker (1985, p.602) puts it: "the test of a healthy business is not the beauty, clarity or perfection of its organizational structure, it is the performance of people".

Next to the involvement of employees for productivity improvement, said involvement is also essential for a focus on quality, as well as on service and customer orientation (Hoogervorst, 1998). Moreover, one might observe that the character of work has shifted, for a considerable part, from physical labour to intellectual labour: creating, processing, integrating and applying knowledge (Drucker, 1991, 1992). It is virtually all about making knowledge productive (Drucker, 1993). Within this perspective, enterprise learning $^{3}$ is, and will increasingly become, an indispensable competence. Learning is a prerequisite for innovation, adaptation and change. Again, the focus on employees is crucial. Evidently, a learning enterprise is inconceivable without the individual learning of employees, on whose skills and commitment enterprise learning rests (Argyris and Schön, 1978; Kim, 1993). This type of learning acknowledges the non-planned, emerging character of many enterprise developments (Hoogervorst, 2009). Hence, employee involvement and participation is essential for addressing enterprise dynamics, complexity, and uncertainty. Enterprise change, hence redesign, is thus fuelled by enterprise learning. As Weick (2001) observes, redesign is a continuous activity whereby the responsibility for (re)design is dispersed and rests with enterprise members who are coping with the 'unexpected'.

\subsection{Other approaches to enterprise development}

Over the years, various other approaches have been proposed in addition to, or as a replacement for, Taylor's principles of scientific management in order to enhance enterprise performance, or to manage change. The list is impressive: activity-based costing, balanced score card, business process management, business process reengineering, customer relationship management, e-business, end-to-end (supply) chain management, enterprise resource planning, lean production, learning organisation, mergers and acquisitions, quality function deployment, Six Sigma, total quality 
management, and so on. Many, if not all, of these initiatives heavily depend on the successful utilisation of ICT services.

Based on reviews of these approaches, their successful application in enterprises is limited: the majority of initiatives showed less than the expected results (referenced in Hoogervorst, 2009). Also from the general perspective on enterprise strategic initiatives, the picture is not overly favourable. Mintzberg (1994) speaks of less than $10 \%$ success rate. Other sources show comparable figures. According to Kaplan and Norton (2004), many studies show that between $70 \%$ and $90 \%$ of strategic initiatives fail, meaning that the expected results are not achieved. Based on an extensive literature research, Keller and Price (2011) conclude that no progress has been made since Kotter's (1996) publication. Whereas all too often, for convenience sake, unforeseen or uncontrollable events are presented as the causes of failure, research has shown that strategic failure is mostly the avoidable result of inadequate strategy implementation. Rarely is it the inevitable consequence of a poor strategy. A plethora of literature indicates that the key reason for strategic failures is the lack of coherence and consistency, collectively also called congruence, among the various components of an enterprise. This notion has been reported from various angles, such as organisational change programmes (Beer et al., 1990; Kaufman, 1992; Miles and Snow, 1984), quality and service improvement (Hevner, 2007), strategic transformation (Kotter, 1988; Leinwand and Mainardi, 2010; Pettigrew, 1998), and enterprise redesign (Miles et al., 1995).

Enterprise engineering is a new, holistic approach to address enterprise changes, of all sizes and in all kinds of enterprises. Because of its holistic, systemic, approach, it resembles systems engineering (Sage, 1992; Stevens et al., 1998). But it differs from it in an important aspect: enterprise engineering aims to do for enterprises (which are basically conceived as social systems) what systems engineering aims to do for technical systems.

\subsection{The crucial role of ICT}

Progress in the area of information and communication technology (ICT) has enabled the creation of massive amounts of data associated with enterprise processes. Work is no longer merely automated (to enhance productivity), but 'informated' (Zuboff and Maxmin, 2002). As indicated earlier, work has almost become synonymous with 'knowledge work': the processing of physical assets is increasingly replaced or complemented by the processing of intellectual assets (Drucker, 1991, 1993). Making knowledge productive thus amounts to integrating knowledge (information) into a common task. Creating and sharing knowledge is considered crucial for gaining competitive advantage (Nonaka and Takeuchi, 1995). Evidently, this holds likewise for the competence of enterprise learning. It seems superfluous to stress the importance of ICT for enterprise learning, hence for the ability to improve, adapt, and change. Without enterprise learning, these changes cannot be established.

From the perspective of the 'relationship economy' the new capabilities and possibilities created by information and communication technology are essential for successfully pursuing long-standing relationships with customers, and for employees supporting them. The vast amount of actions and data pertinent to customers, and their relationships, desires and needs, can only be meaningfully and effectively addressed with the help of ICT. Deep support cannot take place outside the digital medium (Zuboff and Maxmin, 2002). Additionally, ICT makes customer self-support possible and valuable. Moreover, since establishing relationships cannot take place within the principles of the 
transaction economy, the nature of ICT utilisation must change; not only for effectuating customer support and proactively exploiting the relationship in a value-adding manner, but also for making the economic value of customer relationships explicit.

Finally, one can observe the increasing 'commoditisation' of basic products and services. Customers can easily switch between suppliers of commodities. However, highly valued individual supportive relationships with customers are anything but a commodity. Hence, they can create considerable competitive advantages. Despite these advantages, however, the wide penetration of ICT causes an enormous increase in the complexity of the design of ICT applications.

\subsection{Enterprises as organised complexities}

Creating a unified and integrated enterprise is by no means simple. An enterprise is an intentionally created entity of human endeavour (Robbins, 1990; Daft, 2001). Enterprises are organised complexities (Weinberg, 2001): highly complex, as well as highly organised. Unlike problems of 'organised simplicity' that can be dealt with analytically, or problems of 'unorganised complexity' that can be addressed statistically, the large problem area of 'organised complexity' is in need of a formal approach (Weinberg, 2001). The apparent lack of a theory for addressing the problem of organised complexity was mentioned decades ago as a core problem confronting modern science (Weaver, 1967; von Bertalanffy, 1969). Nonetheless, one might raise the question why general systems theory (GST), lasting for over 50 years, has not been successful in this area. Our brief answer would be that the general system theory lacks methodological concepts to address enterprises in all their facets, and to effectively incorporate insights from the traditional organisational sciences within the enterprise design perspective. Next, GST over-emphasises the function perspective on systems (black-box thinking), to the neglect almost of the construction perspective (white-box thinking).

Adding to this is the observation that enterprises are complex adaptive systems whereby it is impossible to determine the ultimate (operational) reality of the enterprise down to the minute details. Hence, trying to specify such reality exhaustively and mechanically - as some systems engineering approaches suggest - and aiming to control it in every detail, seems useless. Instead one must find appropriate approaches to master enterprise complexity at effective levels (Axelrod and Cohen, 2001).

We are fully aware of the fact that our paper is not the first plea for a discipline of enterprise engineering. For example, more than a decade ago, Martin (1995, p.58) stated that "enterprise engineering is an integrated set of disciplines for building or changing an enterprise, its processes, and systems". With deep insight he foresaw that "a new type of professional is emerging - the enterprise engineer" [Martin, (1995), p.xii]. It coincided with the founding paper by Liles et al. (1995) and the set up of the International Society for Enterprise Engineering ${ }^{4}$, which unfortunately seems not be active anymore. Likewise, the current status of enterprise engineering initiatives as taken by several universities, is unclear. They seem to be mere extensions of the fields of industrial engineering or business process management. Notwithstanding the importance of these fields, the organised complexity of enterprises necessitates in our view a radically renewed attention to the idea of enterprise engineering, so that enterprise design addresses the enterprise holistically, while being based on a sound and rigorous scientific foundation.

At the same time, the need to operate as an integrated whole is becoming increasingly important. Globalisation, the removal of trade barriers, deregulation, and so on, have led 
to networks of cooperating enterprises on a large scale, enabled by the enormous possibilities of modern ICT. Future enterprises will therefore have to operate in an even more dynamic and global environment than the current ones. They need to be more agile, more adaptive, and more transparent. Moreover, they will be held more publicly accountable for every effect they produce. Within enterprise engineering, these 'buzzword like' qualities are made crisp and clear, firmly connected to the generic goals, and achieved through systematic enterprise redesign, guided by design principles.

\section{Motivation for enterprise engineering}

\subsection{The importance of design}

An enterprise is an intentionally created cooperative of human beings with a certain societal purpose. The intentional character of enterprise creation requires design activities. For some, the term 'design' in the context of enterprises has uncomfortable connotations, as it is associated with mechanistic approaches to enterprises: arranging them as if they are machines. The 'social engineering' label is sometimes used to identify the mechanistic view on organisation and management (Tsoukas, 1994). This approach essentially equates management with control, with the associated conviction that by using certain 'controls' management is able to steer the enterprise 'machine' (top-down) within the desired range of operation. The enterprise is thereby assumed to be an objective entity, external to management, which, like a machine, merely needs to be controlled. This appears to be the perspective espoused by Taylor; it has been criticised above.

Our notion of design, however, must be interpreted broadly and seen as devising "courses of action aimed at changing existing (enterprise) situations into preferred ones" [Simon, (1969), p.111]. Indeed, as emphasised earlier, we consider design as an activity based on enterprise learning whereby enterprise members cope with the 'unexpected' much like Weick's metaphor of an 'improvisational theatre' (Tsoukas, 1994), as opposed to the traditional 'architecture' metaphor. This point of view also accommodates the notion of emergence, as discussed in Taylor and van Every (2000). Moreover, and underlining the observation made earlier, the responsibility for (re)design is dispersed and rests with all enterprise members. Design concerns on one hand understanding the strategic intentions that are to be operationalised, and on the other hand, arranging this to happen. As Winograd and Flores (1987, p.3) put it: design concerns "the interaction between understanding and creation".

The focus on design has enormous practical implications, and is associated directly with strategic and operational enterprise success (Nadler and Tushman, 1997). Unfortunately, the importance of design is not generally recognised by management. A fairly recent McKinsey report argued that "most corporate leaders overlook a golden opportunity to create a durable competitive advantage and generate high returns for less money and less risks: making organizational design the heart of strategy". Managers traditionally focus on structural arrangements for enterprise change; however, "they would be better off by focusing on organizational design" [Bryan and Joyce, (2007), p.22]. Hence, "organizational design, we believe, should be about developing and implementing corporate strategy" [Bryan and Joyce, (2007), p.25]. 


\subsection{The needed paradigm shift}

Over the years (academic) insights have been developed about how to

1 enhance the effectiveness and efficiency of enterprises

2 effectively ensure quality, service and customer orientation

3 avoid core reasons for strategic failure (e.g., Beer et al., 1990; Deming, 1986; Nadler and Tushman, 1997; Pettigrew, 1998).

One would expect that a century after Taylor published his principles of scientific management their influence would have vanished. However, it appears not to be the case. As Doz and Thanheiser (1993, p.296) observed at the end of the previous century: "despite the 'modernization' of corporate structures and systems, the mindset of managers appears to be remarkably similar to the Taylorist model developed at the beginning of the century". Thus, principles that follow from "a machine-like concept of the organization still dominate managerial practice" (ibid.). Others argue that "corporations continue to operate according to a logic invented at the time of their origin, a century ago" [Zuboff and Maxmin, (2002), p.3]. Specifically concerning the use of ICT, the picture seems not radically different. Despite the alternative perspectives to Taylor presented in Section 1.2 - including the value-adding, competitive use of ICT - the Taylorist influence is still remarkable. For example, the Butler (2005) group "has consistently found that management in 9 out of 10 companies have never considered the use of ICT other than for achieving labor replacement".

The continuation of the Taylorist model can additionally be demonstrated by observing the increase in the number of management functions. For example, in the country where Taylor expressed his views, managers accounted for less than $1 \%$ of the labour force in 1900 . Thirty years later this figure was already $7.5 \%$, increasing to $10.5 \%$ by 1970 . By 1990, the figure was approaching 14\% (Osterman, 1996). These increases must be understood against the background of increasing population and workforce. Others have given comparable data concerning the magnitude of management positions and the associated administrative burden (Witteloostuijn, 1999).

The increased population of managers largely consists of people who believe that management is a profession like other professions. As Deming (1986, p.130), the renowned quality and productivity leader, observed: "students in schools of business in America are taught that there is a profession of management; that they are ready to step into top jobs. That is a cruel hoax". This 'hoax' resulted in the widely observable management crises. An article in the Standardization News (1983) [Deming, (1986), p.131] stated that "practical all our major corporations were started by technical men inventors, mechanics, engineers, and chemists, who had a sincere interest in the quality of products. Now, these companies are largely run by men interested in profit, not product. Their pride is the P\&L statement or stock report". Detrimental effects of these developments have been documented pertinent to the US automobile industry (Lutz, 2011). Not surprisingly, a recent Time article correlated the rise of business schools with the fall of US industry (Foroohar, 2011).

The needed paradigm shift is provided by the emerging discipline of enterprise engineering. It amounts to a theory-based methodology for addressing enterprise (re-)development in an all-encompassing way. A sound and rigid theoretical foundation is crucial. As Deming (1986, p.19) states: "experience alone, without theory, teaches 
management nothing about what to do to improve quality and competitive position, nor how to do it". In view of our previous discussion, and the tenacity of Taylor's principles, little learning seems to have taken place. We posit that an explanatory theory is required to give experience meaning, so to provide the basis for appropriately understanding enterprises.

\subsection{The generic goals of enterprise engineering}

It is the mission of enterprise engineering to be theoretically, conceptually, and methodologically complete, in pursuing the next three generic goals:

\subsubsection{Intellectual manageability}

Proper theories about the construction and operation of enterprises are needed, in order to get and keep insight and overview concerning enterprises and enterprise changes, and to master their complexities. Enterprise phenomena that are not comprehensively understood, cannot be addressed adequately. Hence, the nature of necessary changes cannot be determined; consequently they cannot be brought about effectively. In addition, current development approaches, for enterprises as a whole and for ICT applications in particular, are cursed with combinatorial impacts of changes, which make their implementation slow and practically unmanageable. So, in addition, appropriate ideas of enterprise evolvability are needed for making changes expeditious and manageable.

\subsubsection{Organisational concinnity}

In order to perform optimally and to implement changes successfully, enterprises must operate as a unified and integrated whole, taking into account all aspects that are deemed relevant. Many approaches to enterprise development, for example TOGAF, are ill suited and suffer from theoretical and methodological weakness and incompleteness (Dietz and Hoogervorst, 2011). It is evidently not sufficient to consider enterprise design domains like processes, the information relevant for the processes, the software applications providing that information, and their underlying infrastructure. A viable theory and methodology for enterprise engineering must be able to address all relevant aspects, even those that cannot be foreseen presently, in a properly integrated way, so that the operational enterprise is always a coherent and consistent whole. It is quite obvious that organisational concinnity must be designed; it does not emerge in a natural way (Keller and Price, 2011; Leinwand and Mainardi, 2010).

\subsubsection{Social devotion}

In Section 1.1, we have argued the importance of employee involvement and participation for enterprise productivity, product and service quality, customer orientation, learning and innovation (and subsequent enterprise change), as well as for coping with enterprise dynamics, complexity, and uncertainty leading to emerging enterprise developments. Contrary to Taylor's mechanistic view on organisations, enterprise engineering takes a human-centred view. It considers human beings to be the 'pearls' of every enterprise. Therefore, all employees should be fully empowered and competent for the tasks they have to perform. They must be endorsed with transparent 
authority and have access to all information they need in order to perform their tasks in a responsible way. Next, managers must not only be skilled in managerial work of the kind that Deming refers to Deming (1986) they must first of all be thoroughly knowledgeable in the subject field of the enterprise they are managing.

\section{Enterprise engineering theories}

In this section, a number of theories are discussed that we consider foundational to the discipline of enterprise engineering. Some of them are already quite well developed, and some may even be qualified as rather mature. But many theories need substantial further development or improvement, and some may still have to be added. The list of theories, as presented in Figure 1, and as briefly discussed in Section 3.2, can therefore usefully be considered as a, non-exhaustive, theoretical research agenda for the enterprise engineering community. Next to this agenda, a practical research agenda has to be produced. There is an urgent need to provide the substantial and appropriate practical evidence that enterprise engineering delivers the benefits we claim in this article. Such a practical research agenda will consist of case studies, comparative reviews, and other experience-based evaluations.

\subsection{Classes of theories}

In order to present and discuss the enterprise engineering theories in a rigorous and lucid way, a suitable classification scheme is needed. The scheme we have developed to serve this purpose, is exhibited in Figure 1. It is partly based on the one that was developed for the social sciences, in particular for the economic sciences, by Chmielewicz (1994).

Figure 1 EE theories in the classification scheme (see online version for colours)

\begin{tabular}{|c|c|c|}
\hline \multicolumn{2}{|c|}{$\begin{array}{l}\text { Ideological theories } \\
\text { devising and choosing things to make } \\
\text { ethical, political, etc. ideas } \\
\text { EE-theories: } \sigma \text {-theory }\end{array}$} & $\begin{array}{l}\text { Technological theories } \\
\text { designing and making things } \\
\text { analysis and synthesis } \\
\text { EE-theories: } \beta \text {-theory, } v \text {-theory }\end{array}$ \\
\hline & \multicolumn{2}{|c|}{$\begin{array}{l}\text { Ontological theories } \\
\text { understanding the nature of things } \\
\text { explanation and prediction } \\
\text { EE-theories: } \psi \text {-theory, } \pi \text {-theory }\end{array}$} \\
\hline \multicolumn{3}{|c|}{$\begin{array}{l}\text { Philosophical theory } \\
\text { theoretical foundations } \\
\text { epistemology, mathematics, phenomenology, logic } \\
\text { EE-theories: } \phi \text {-theory, } \delta \text {-theory, } \tau \text {-theory }\end{array}$} \\
\hline
\end{tabular}


Four classes of theories are distinguished, which we label 'philosophical', 'ontological', 'technological' and 'ideological'. We consider the four classes of theories to be related to each other in the way as presented in Figure 1. An arrow between two classes means that every theory in the class on the arrow side is based on a number of theories (possibly none) in the class on the shaft side. The contained theories in enterprise engineering will be elaborated in Section 3.2.

Philosophical theories are theories that address very basic conceptual matters. They include the philosophical branches of epistemology and phenomenology, as well as logic (in all of its variants) and mathematics.

Philosophical theories are valuated by their truthfulness within a chosen area. The truthfulness of a philosophical theory is established by reasoning, and/or by judging its tenability in the face of reality. Regarding logical and mathematical theories, this reasoning can mostly be exact. In the other branches of philosophy, such exactness is mostly not possible.

Ontological ${ }^{5}$ theories are theories about the nature of things. They address explanatory and/or predictive relationships in observed phenomena. Within the discipline of enterprise engineering, we are particularly concerned with cause-effect relationships in systems. These relationships are (or must be) able to explain observed behaviour, as well as to predict behaviour to some extent, based on the ontological understanding that the theory provides. An important note has to be made with respect to social science theories in general. Although they belong to the class of ontological theories within our framework, they often are only able to show statistical correlations between phenomena. Such correlations, however, are not cause-effect relations; the latter require the inclusion in the theory of some 'mechanism' by which events can be clearly explained as the effects of particular acts (the causes).

Ontological theories are valuated by their soundness and their appropriateness. The soundness of an ontological theory is established by its being rooted in sound philosophical theories. The appropriateness of an ontological theory is established by the evaluation of its practical application, e.g., through expert judgments.

Technological ${ }^{6}$ theories are theories that address means-end relations between phenomena. Obviously, this is the core area of engineering (of all kinds). Technological theories are the foundation of design methods. A method that is firmly rooted in an technological theory, is often called a methodology. As Alexander (1960) puts it, a design process is basically a process of analysing a problem (a situation that one considers undesirable) and synthesising a solution (a situation that one considers desirable). After having conceived the solution in all detail, it can be implemented, such that the new situation can be made operational. Implementing is assigning concrete means to the elements of the implementation model. Unfortunately, the term 'technology' has become a (confusing) synonym for technical means, like ICT.

Technological theories are valuated by their rigor and their relevance (Hevner, 2007). The rigor of a technological theory is established by its being rooted in sound ontological theories. The relevance of a technological theory is established by the evaluation of its practical application, e.g., through measurements, in evaluative comparisons, and in adoption studies.

Ideological theories are theories that address the goals people may want to achieve in society at large, and for us, in enterprises in particular. Ideological theories are fuelled by visions, convictions and beliefs. Therefore, they are by nature subjective, in contrast to 
the objective ontological and technological theories. The role of ideological theories in enterprise development is to guide the devising and/or choosing of the changes that are considered necessary, and that consequently have to be accomplished.

Ideological theories cannot a priori be predicated as truthful or sound and appropriate, nor as or rigorous or relevant, even if they are rooted in rigorous and relevant other theories. One can only speak of their societal significance. The significance of an ideological theory boils ultimately down to its fruitfulness and utility, as determined by its supporters.

\subsection{Theories in enterprise engineering}

\subsubsection{The $\phi$-theory}

The $\phi$-theory ( $\phi$ is pronounced as FI, standing for fact and information) is a theory about the nature of factual knowledge. It provides the basis for an appropriate understanding of what is commonly referred to by terms like 'fact', 'data', 'information', and 'knowledge'. By that matter, it constitutes the theoretical foundation of all conceptual models in the other EE-theories. Core notions in the theory are the semiotic triangle (Morris, 1938) and the ontological parallelogram (Dietz, 2006). The $\phi$-theory is rooted in semiotics (Peirce, 1958; Morris, 1938), in logic (Wittgenstein, 1922; Sowa, 2000), in philosophical ontology (Bunge, 1977), and in mereology (Simons, 1987). It is extensively discussed in Dietz (2005a) and in Dietz (2006) ${ }^{7}$.

\subsubsection{The $\delta$-theory}

The $\delta$-theory ( $\delta$ is pronounced as DELTA, standing for discrete event in linear time automata) is a theory about the statics, kinematics, and dynamics of discrete event systems. It provides the basis for an appropriate understanding of what is commonly referred to by terms like 'system', 'state', 'event', and 'process'. By that matter, it constitutes the theoretical foundation for the formalisation of the $\psi$-theory and the $\pi$-theory, as well as of approaches to the discrete event simulation and animation of organisations and software systems.

The $\delta$-theory is rooted in systemic ontology (Bunge, 1979), and in automata theory (Hopcroft and Ullman, 1979). It is extensively discussed in Dietz and van Hee (1988), van Hee et al. (1989) and in Dietz (2006). The $\delta$-theory builds on the $\phi$-theory.

\subsubsection{The $\tau$-theory}

The $\tau$-theory ( $\tau$ is pronounced as TAO, standing for teleology across ontology) is a theory about system perspectives. It particularly clarifies the notions of teleology and ontology, their fundamental difference as well as their relationship. Thereby, it provides the basis for an appropriate understanding of what is commonly referred to by terms like 'system', 'model', 'function', and 'construction'.

The $\tau$-theory is firmly rooted in systems thinking (von Bertalanffy, 1969; Bunge, 1979; Checkland, 1981). It is extensively discussed in Dietz (2008), in Hoogervorst (2009) and in Dietz (2006). 


\subsubsection{The $\psi$-theory}

The $\psi$-theory ( $\psi$ is pronounced as PSI, standing for performance in social interaction) is a theory about the ontological essence of organisations. It clarifies and explains the construction and operation of organisations. The operating principle of enterprises is that actors (employees, customers, suppliers) enter into and comply with commitments regarding the products (services) that they produce in cooperation. This basic understanding makes enterprises primarily social systems, of which the elements are human beings in their role of social individuals, bestowed with appropriate authority and bearing the corresponding responsibility.

The $\psi$-theory provides us with an effective notion of enterprise ontology, defined as the fully realisation and implementation independent understanding of the (constructional) essence of an enterprise's organisation (Note: this does not say anything about the functional essence of the enterprise as perceived by its various stakeholders: shareholders, employees, management, etc.).

The $\psi$-theory is rooted in speech act theory (Austin, 1962; Searle, 1969), in social action theory (Habermas, 1984), and in information systems theory (Langefors, 1977), and it is extensively discussed in Dietz (2006). It builds on the $\delta$-theory and the $\phi$-theory.

\subsubsection{The $\pi$-theory}

The $\pi$-theory ( $\pi$ is pronounced as PI, standing for performance in interaction) is a theory about the ontological essence of systems of which the elements are non-human (therefore the $\mathrm{S}$ for social is missing in the name). In order to avoid misunderstandings, we will call these systems 'technical systems'. Note that a technical system may be (originally) a social system, only technically implemented, like automated teller machines (ATM), automated check-in systems, and web shops. The $\pi$-theory clarifies and explains the construction and operation of technical systems. The operating principle of these systems is that agents interact through commands. The addressee of a command will respond to it in a deterministic way (unlike human beings do). The response consists of the bringing about of some product or service and/or the generation of one or more commands.

The $\pi$-theory is discussed to some extent in Dietz $(2006,2005 \mathrm{~b})$. It builds on the $\delta$-theory and the $\phi$-theory.

\subsubsection{The $\beta$-theory}

The $\beta$-theory ( $\beta$ is pronounced as BETA, standing for binding (constructional) essence, technology, and architecture) is a theory about the design of (discrete event) systems. It provides the basis for an appropriate understanding of what is commonly referred to by terms like 'development', 'design', 'engineering', and 'implementation'.

The $\beta$-theory is rooted in systems thinking (von Bertalanffy, 1969; Bunge, 1979; Checkland, 1981), in general design theory (Simon, 1969), and in software design theory (Dijkstra, 1976). It is extensively discussed in Dietz $(2008,2006)$ and in Hoogervorst (2009). The $\beta$-theory also offers an appropriate and effective notion of enterprise architecture, defined as the deliberate restriction of design freedom, and of enterprise design, which covers the function design, construction design, and implementation design phases in the generic system development process (Dietz, 2008). It builds in particular on the $\tau$-theory and the $\delta$-theory. 


\subsubsection{The v-theory}

The $v$-theory ( $v$ is pronounced as NU, standing for normalised unification) is a theory about the construction of (discrete event) systems. The construction of a system is called normalised if a change consists of a set of elementary changes, so that every elementary change is the addition or the removal of an element. Put differently, in a normalised system the impact of an elementary change is only such an addition or removal, without combinatorial side effects (i.e., without needing to add or remove other elements).

Concerning software systems, the $v$-theory is extensively discussed in Mannaert and Verelst (2009), under the name 'normalised systems' (NS). This software engineering approach avoids the combinatorial effects of bringing about changes in software (Lehman, 1980). In addition, very short delivery and test times are achieved. The NS theory is rooted in software design theory (McIlroy, 1968; Lehman, 1980). Concerning systems in general, the $v$-theory has to be further developed. The $v$-theory builds in particular on the $\delta$-theory.

\subsubsection{The $\sigma$-theory}

The $\sigma$-theory ( $\sigma$ is pronounced as SIGMA, standing for socially inspired governance and management advancement) is a theory about the way modern enterprises should be constituted, in particular how they should be governed and managed. It is rooted in landmark publications of organisational theorists arguing the crucial importance of the social aspects of enterprises (Drucker, 1985; Katz and Kahn, 1978; Likert, 1965; McGregor, 1960). Congruent with our previous observations, this social, hence human-centred perspective is not only essential in view of enterprise performance, learning and change; it also offers demonstrably the largest contribution to managerial effectiveness (Luthans, 1977; Yukl, 2002; Drucker, 1985; Katz and Kahn, 1978; Likert, 1965). The $\sigma$-theory conveys the 'unitarist' view on enterprise development by rejecting the necessary conflict between enterprise interests and employee interests (Likert, 1965).

Effectively applying the $\sigma$-theory is evidently in itself an aspect of enterprise design. As such, the theory builds heavily on the $\tau$-theory, which, on its turn, builds heavily on the $\psi$-theory, as we have seen. The $\sigma$-theory is partly discussed in Hoogervorst (1998, 2009). For the other part it has to be further developed yet.

\subsection{Methodological foundations of enterprise engineering}

As a final remark concerning the classification scheme for theories, we want to discuss the role of scientific methodologies in enterprise engineering. March and Smith (1955) distinguish between 'natural sciences' and 'design sciences'. Natural sciences are concerned with understanding and explaining observable phenomena around us. Examples of natural sciences are physical, biological, social, and behavioural sciences. Specifically regarding enterprises, social and behavioural sciences seek to understand, explain and predict organisational and human phenomena (Hevner et al., 2004). Therefore, these natural sciences would belong to the class of ontological theories in Figure 1. The other important scientific domain is identified as 'design sciences' (Simon, 1969). The latter type of science is concerned with devising artefacts or other intentionally created results. Therefore, these sciences would belong to the class of technological theories in Figure 1. To further illustrate the distinction between natural 
sciences and design sciences, one might say that natural sciences are about finding out how things are, whereas design sciences are about finding out what is effective (Hevner et al., 2004). Put differently, design sciences are about prescribing how things have to be created (March and Smith, 1955).

Obviously, an effective design science must have its fundaments in the natural sciences. So, e.g., proper aircraft design rests on theories and concepts from aerodynamics, metallurgy, chemistry, and so on. In view of the multitude of aspects relevant for enterprises, the theoretical basis for enterprise design is inherently broad. Various natural sciences play a role, as expressed by the theories in enterprise engineering discussed earlier. Also within the enterprise context, the danger of not maintaining an adequate 'theory base' has been identified (Hevner et al., 2004). Many approaches concerning enterprise design can be noticed with a focus on models and representations, whereby adequate attention to the theory base can be questioned (Dietz and Hoogervorst, 2011).

The so-called design science research (DSR) methodology seems an appropriate candidate for being the main research methodology in enterprise engineering. It is also already quite widely accepted, notably in the information systems area (cf. March and Smith, 1955; Hevner et al., 2004). Because enterprise engineering is by nature about designing, we take DSR as the scientific foundation for justifying research in enterprise engineering. A concise description of the DSR methodology is provided by Hevner (2007).

\section{Enterprise engineering fundamentals}

In order to achieve the generic goals of enterprise engineering, as presented in Section 2, we have formulated seven fundamentals for dealing effectively with enterprise design, enterprise governance, and enterprise management. The changes that are addressed range from small ones (like installing a new e-mail system) to major transformations (like mergers and acquisitions). The fundamentals must be understood as ideas that we consider to be prominent in enterprise engineering. All of them are already included in one or more of the previously discussed theories. By formulating them explicitly as fundamentals, they are considered to constitute guidelines that are more readily adopted in practice than the theories themselves. A detailed presentation of the methodologies in enterprise engineering exceeds the scope of this article; they are discussed elsewhere (Dietz, 2006, 2008; Hoogervorst, 2009, 2011). For now, we limit ourselves to presenting the fundamentals of enterprise engineering (cf. Figure 2).

Fundamentals 1, 2, 3, and 4 serve to make enterprise design practically doable and manageable. They help to bring about changes in such a way that intellectual manageability and organisational concinnity are achieved, paired to avoiding combinatorial explosions of change impacts.

Fundamentals 5, 6, and 7 are ideological fundamentals. They convey our conviction that the employees of an enterprise primarily constitute the enterprise, and that consequently they must get the proper empowerment to perform optimally. Put differently, in our view, enterprises are participatory networks of competent people. The employees of an enterprise (including both workers and managers) also collectively constitute the enterprise's identity. In economic terms, they are the most precious asset. 
Everything else only serves to support them in their work. All of them contribute to achieving the goal of social devotion.

Figure 2 EE generic goals and fundamentals in the classification scheme (see online version for colours)

THEORY CLASS

\begin{tabular}{l}
\hline Ideological \\
devising and choosing things \\
to make \\
ethical, political, etc. ideas
\end{tabular}

Technological designing and implementing things

analysis and synthesis

Ontological

understanding the nature of

things

explanation and prediction

\section{Philosophical}

theoretical foundations

epistemology, mathematics,

phenomenology, logic
GENERIC GOAL

FUNDAMENTALS
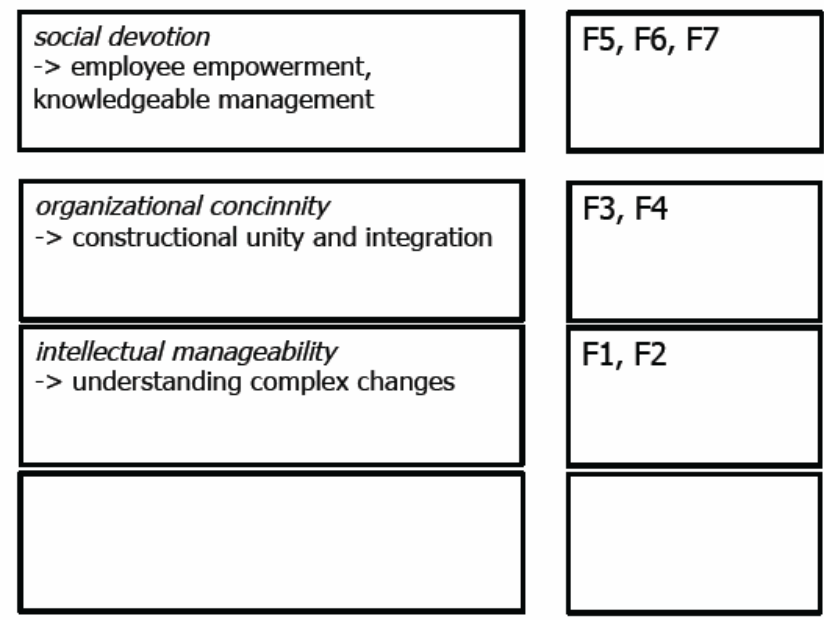

\subsection{Fundamental 1: strict distinction between function and construction}

In (re-)developing an enterprise, the conscious distinction between a system's function and construction, and the insight in their alternating roles in system development, is of paramount importance. As posited by the $\tau$-theory, only the construction of a system is objective. A constructional model (or white-box model) of an enterprise, can always be validated from the actual construction. Contrarily, a functional model (or black-box model) is by its very nature subjective, because function is not a system property but a relationship between the system and a stakeholder. Consequently, every system has (at any moment) one construction, but it may have at least as many functions as there are stakeholders. All these functions are brought about by the (same and only) construction. Next, the construction of a system as a composition of sub systems can only be understood through the alternating roles of function and construction. As an example, the functional specifications for the engines of an aircraft are derived from the constructional model of the aircraft, not from the aircraft's functions. Conversely, the actual construction of the engines is immaterial for understanding the (global) construction of the aircraft.

Whatever objective anyone of the stakeholders wants to achieve by (the development of) a system, it has to be expressed first in functional requirements or functional design principles. All common considerations in current systems development, like user orientation, service orientation, and value orientation, have to be accommodated in the function design of the system (see also fundamental 2 and fundamental 3).

Also according to the $\tau$-theory, the function design of an object system must start from the ontological model of the using system. Based on the functional model of the 
object system, its ontological construction model is designed. Then, the engineering (or implementation design) of the object system can take place.

A logical consequence is, that it makes no sense to develop enterprise information systems, starting from the goals of the enterprise (although many approaches makes one believe so). Another consequence is, that business IT alignment can never be achieved through IT governance (although many approaches makes one believe so), because one lacks the knowledge of the organisation, i.e. the construction of the enterprise.

A third important consequence is the insight that every operational enterprise information system is some implementation of (some part of) the essential model of the enterprise. The question, however, is: which one? Since in current information system development practice, essential models of the supported enterprise are not produced, one should not be amazed that these systems (including parameterisable ERP systems) do not meet customer expectations.

Applying fundamental 1 contributes primarily to the achievement of the generic goal intellectual manageability.

\subsection{Fundamental 2: focus on essential transactions and actors}

The complexity of enterprises necessitates a division of tasks to be performed. Because the enterprise must operate as a unified whole, task differentiation must be properly paired to the integration of the distinct tasks. The organisational sciences have for long recognised the non-trivial issues of differentiation and integration (Daft, 2001; Lawrence and Lorsch, 1967). However, an effective approach to identify tasks is still lacking.

In view of the argued employee focus, organisational performance ultimately concerns the performance of employees: they are the only ones that can be bestowed with authority and responsibility. This is the core of the $\psi$-theory: performance in social interaction. The notion of differentiation implies that employees are engaged in numerous different production activities (e.g., concluding an insurance policy, making an equipment part, paying an invoice, or giving a permission), whereas the notion of integration demands that these activities are coordinated such that the enterprise operates as an integrated whole. The $\psi$-theory provides us with the insight that the coordination and production activities occur in universal patterns called transactions (Dietz, 2006). These are the elementary (essential) organisational building blocks of enterprises. Enterprises have dozens of processes, such as for production, recruitment, purchasing, payment, accounting, logistics, and so on. Despite their different nature, they all share the same underlying transaction patterns. Every business process appears to be a tree structure of transactions. This holds also for non-operational processes, like support and management processes (Aveiro et al., 2011).

Another major contribution of the $\psi$-theory to mastering the complexity of organisations emerges from the distinction between an enterprise's B-organisation (from business), I-organisation (from information), and D-organisation (from data and document) (Dietz, 2006). The $\psi$-theory-based ontological model of the B-organisation of an enterprise is called its essential model. By adopting this distinction, next to the organisational building block from the $\psi$-theory, a reduction in the size of enterprise models is achieved, and in the time to produce them, of well over $90 \%$. Consequently, a major contribution is offered to making enterprises intellectually manageable. In the end, essential models need to be realised and implemented, for which much more detailed 
models have to be produced, guided by enterprise architecture (cf. fundamental 4). In addition, it seems to be the best guarantee that even the most encompassing enterprise changes will not lead to severe combinatorial explosions of effects (following the $v$-theory). Moreover, attention to the enterprise essence makes clear that similar enterprises have similar underlying essential designs. Understandably, this is the case for municipalities, police forces, banks, and airlines, to name but a few.

Opportunities for re-use of functionalities or services already developed become manifest and applicable through knowledge of the implementation-independent organisational essence of an enterprise. An interesting extension of this idea towards software engineering is presented in Albani and Terlouw (2010), where the notions of service and of business component are based on these organisational building blocks.

Applying fundamental 2 contributes primarily to the achievement of the generic goal intellectual manageability.

\subsection{Fundamental 3: rigorous distinction between design and implementation}

The $\beta$-theory fully explains and clarifies the complete development process of a system, consisting of three phases: function design, construction design, and engineering ${ }^{8}$ (also called implementation design) (Dietz, 2008). By implementation we mean the concrete realisation of a system. Put differently, implementation concerns the activities for putting a design into effect. Unlike the other two phases, engineering is a rather deterministic process executed according to some plan: a precisely defined, detailed scheme of activities, for accomplishing a clearly defined objective. Such activities can be executed and managed as a project. Generally, one has to iterate through the mentioned phases of the total development process. One might, e.g., discover during implementation that the designed and engineered system is not feasible. In such a case, the system has to be (partly) re-designed and re-engineered.

Contrary to engineering, design is a highly non-deterministic process. It amounts to unrestrictedly exploring design possibilities rather than restrictedly following a predefined, formalised plan. In the function design phase, the functional (black-box) model of the object system, i.e., the system to be developed, is produced, starting from the given functional requirements and the functional principles in the applicable architecture. Ideally, the functional requirements are based on the essential model of the using system, i.e., the system that is going to be supported by the object system. In the construction design phase, a highly abstracted constructional model of the object system is produced, starting from the functional model. Ideally, this abstract model is an ontological model, which means that it is fully independent of the way it is or will be implemented.

Consequently, design activities cannot be executed and managed as a project. Applying implementation-type concepts to design activities amounts to confusing creativity with execution and planning. Design must be considered as an activity of professionals with an inherently unpredictable outcome and duration.

In terms of the notion of system lifecycle, enterprise engineering is concerned with all activities up to the implementation stage, as defined above. Utilisation of the (implemented) system pertains to the operational utilisation of the system, which also includes support activities such as maintenance. However, should the system be modified in order to change some system properties, redesign must take place that basically 
follows the same process up to the new implementation and subsequent utilisation. Formally, the lifecycle ends when the system is decommissioned.

Because the essential model of an enterprise provides an unprecedented insight and overview in the construction and operation of its organisation, it is the highly recommended starting point in every change activity. A very interesting new way of developing enterprise information systems, taking advantage of the properties of essential models, is presented in van Kervel et al. (2012). It generates enterprise information systems directly from the essential model of the enterprise, as a kind of real-time simulation. Moreover, fundamental 2 is not limited to the operational processes in an enterprise. It is applicable to all activities, as proposed in Aveiro et al. $(2010,2011)$, where proposals are presented for the extension of $\mathrm{DEMO}^{9}$, in order to accommodate control and change in an organisation.

Applying fundamental 3 contributes primarily to the achievement of the generic goal organisational concinnity.

\subsection{Fundamental 4: diligent application of design principles}

It is one thing for an enterprise to have clear strategic goals and areas of concern, derived from a broadly sustained mission statement. It is quite another thing to have all operational details in the enterprise's organisation fully compliant with them. The challenge is to align strategy and operation in a satisfying way.

To ensure that an enterprise operates in a unified and integrated manner, and in compliance with its strategic intentions and areas of concern, the development process of enterprises and of their supporting systems must be controlled by functional and constructional design principles, which guide the (re-)design of the enterprise, in addition to the applicable specific functional and constructional requirements. A coherent, consistent, and hierarchically ordered set of such principles for a particular class of systems is called an architecture. The collective architectures of an enterprise at some moment are called the enterprise architecture at that moment. Requirements pertain to a specific system to be designed, whereas architecture pertains to a system class (such as accounting systems or sales departments). Indeed, requiring a user-friendly web interface or a certain level of system availability, does not provide sufficient guidance as to how to satisfy the requirement. Such general and often high-level strategic requirements must be made operational through constructional design principles.

As the $\beta$-theory posits, the notion of architecture can best be conceived as the deliberate, normative restriction of design freedom, which comes in addition to the specific functional and constructional requirements in (re-)designing a system, e.g., an organisation. It is expressed in (functional and constructional) design principles regarding a number of areas of concern and applied in one or more enterprise design domains (Dietz, 2008, Hoogervorst, 2009). So, for example, the concern for motivated employees must be addressed through appropriate design principles that are applied in relevant enterprise design domains. An extensive study of architecture principles is contained in Greefhorst and Proper (2011).

Applying fundamental 4 contributes primarily to the achievement of the generic goal organisational concinnity. 


\subsection{Fundamental 5: distributed operational responsibility}

The objective of employee empowerment, as part of the goal social devotion, implies that as much responsibility as possible is given to the individual employees. It does not go along with strong hierarchical control mechanisms. On the contrary, many management or control measures are counterproductive and redundant. This is a common observation in numerous enterprise studies that have been undertaken with DEMO. A typical example is the organising of an employee's work. It is our conviction that the ideal person to organise somebody's work is the worker him- or herself, provided that he/she has access to the information needed. Responsibility is the natural response of a human being to whom full authority is assigned for performing a task or fulfilling a role. Moreover, responsible employees are dedicated to achieve the optimal performance of an enterprise in all aspects. This manifests an important paradigm shift from employee control to employee support. There is ample practical evidence for our conviction, as exemplified by enterprises like Alcoa Inc, W.L. Gore \& Associates, Nordstrom, and Semco.

Moreover, we consider it to be an ethical necessity to bestow authorities on the employees of an enterprise, and having them bear the corresponding responsibility. The prerequisite is that they fully understand their role(s) in the enterprise. This entails that the employees are enabled to internalise the (relevant parts of the) ontological model of the enterprise, as put forward by the $\psi$-theory. Bearing responsibility includes that these employees constantly validate the correspondence of the ontological model with the operational reality and take appropriate measures in case of deviations. The central role of employees as expressed by this fundamental is similarly important for the ability of employees to create and share knowledge, which in turn is the primary condition for enterprise learning and the capacity to create and address emerging (non-planned) developments.

Applying fundamental 5 contributes primarily to the achievement of the generic goal social devotion, powered by the $\sigma$-theory.

\subsection{Fundamental 6: distributed governance responsibility}

For continuously maintaining unity and integration in the (re-)development and operation of an enterprise, organisational measures are needed that exceed operational responsibilities and tasks (including management). These measures are collectively called governance. Hence, unlike operational management ('running the mill') governance concerns enterprise adaptation and renewal ('changing the mill'). Very often, the responsibility for taking and applying such measures on a continuous basis, usually called enterprise governance, is assigned to higher levels of management. Factually, this amounts to the continuation of the Taylorist separation of thinking (management) and doing (workers): the locus of knowledge and control rests with executive management. Such an approach is inherently problematic and dysfunctional (Hoogervorst, 2009).

Indeed, how could executive management possibly know and comprehend all internal (operational) issues and external developments that necessitate enterprise change and adaptation, and translate them in top-down directives that would innovatively yield a new, adapted, unified and integrated enterprise? We posit that it is essential to extend the notion of employee involvement also to the realm of enterprise governance. As stated 
earlier, enterprise change is based on enterprise learning, which in turn is based on individual employee learning. All employees are thus considered creative sources for (bottom-up) enterprise improvements and adaptation. Of course, they must be enabled and competent to do so. Further, by capturing the history of organisational changes (including alternative change options and lessons learned) and by identifying future change options, we can make valuable organisational knowledge available, in order to empower employees and managers, and to contribute to relevant future organisational changes and learning. In order to ensure coherence and consistency in the development and implementation of new ideas and ways of working, a central governance capability must be exercised at the holistic enterprise level. This central guiding governance capacity utilises the enterprise engineering theory and methodology for achieving the generic objectives mentioned before.

Note that IT governance is an integral part of enterprise governance, despite the many views that do not acknowledge or adequately operationalise this notion due to the absence of a focus on enterprise-wide design (IT Governance Institute, 2003; Maizlish and Handler, 2005).

Applying fundamental 6 contributes primarily to the achievement of the generic goal social devotion, powered by the $\sigma$-theory.

\subsection{Fundamental 7: human-centred and knowledgeable management}

As has been amply stressed before, our ideological position underpinning enterprise engineering, is based on the crucial role of employees. This is expressed by the generic goal of social devotion, as well as by the fundamentals 5 and 6. Ultimately, enterprise performance is determined by the performance of its people (Drucker, 1985). This human-centred ideological position has been widely argued within the traditional organisational sciences (Katz and Kahn, 1978; Likert, 1965; McGregor, 1960). An evident consequence of the crucial role of employees is the human-centred nature of management. Miles et al. (1995) identified a clear managerial philosophy that establishes continuous development of human assets as the key element of success in corporate redesign. That is, management must be primarily concerned with creating conditions for employees doing their work and developing themselves accordingly. Put differently, human-centred management provides the conditions for mobilising and maintaining the intensity of employee involvement and participation. It fits within the 'unitarist' notion of the $\sigma$-theory mentioned before.

If employee participation and involvement is to mean anything, it has to be at the level of self-management. This condition necessarily implies a departure from tight (instrumental) managerial control: empowerment of employees must be complemented by management enablement. This shift in behavioural guidance subsequently implies a shift from management in its traditional form towards management as leadership. The essential characteristics of leadership have been extensively discussed (Burns, 1979; Kotter, 1988; Bennis, 1989; Yukl, 2002). Control and supervision characterises the traditional, instrumental, contractual, and unidirectional management relationship with employees. Leadership on the other hand implies a bidirectional relationship, based on shared purpose, goals, norms, and values. Underlying all forms of leadership is the notion of mutuality: both leaders and followers have no meaning on their own. Their interrelation is foundational and based on mutual trust. Leadership may be defined as "inducing followers to act for certain goals that represent the values and motivations - the 
wants and needs, the aspirations and expectations - of both leaders and followers" [Bennis, (1989), p.19]. Leadership is about stimulating self-confidence and self-efficacy of followers (employees), which in turn leads to self-actualisation. Hence, leadership turns potential into reality. The notion of mutuality also follows from the fact that leaders guide, but are also guided by followers. It is argued that leadership is required at all organisational levels (Kotter, 1988).

Providing behavioural guidance through shared purpose, goals, norms and values ultimately boils down to providing meaning such that individuals orient themselves to the achievement of desirable ends (Smircich and Morgan, 1982). We submit that defining meaning and purpose for employees necessitates knowledge and insight into their roles and activities. Hence, it implies that management in their leadership capacity is thoroughly knowledgeable about the domain they are managing. Indeed, the needed paradigm shift discussed in section 2.2 was based on the argued detrimental effects of seeing management as just a profession that can be exercised to any enterprise, irrespective of its specific nature. A management position in a hospital can thus be easily exchanged for one in a steel factory. Already decades ago this perspective has been severely criticised (Deming, 1986).

Applying fundamental 7 contributes primarily to the achievement of the generic goal social devotion, powered by the $\sigma$-theory.

\section{Discussion and conclusions}

Enterprises are purposeful entities of human endeavour, and they come in a wide range of forms and dimensions. Arguably, society is largely constituted and dominated by enterprises. For healthcare, education, transportation, or the production and acquisition of commercial and governmental goods and services, individuals depend on, and are influenced by, the characteristics and performance of enterprises, as citizen, consumer or employee. Hence, the characteristics and performance of enterprises has a bearing on the quality of life and society at large: societal and environmental conditions, the quality of work and private life, individual physical and mental health, and economical circumstances: they all are impacted by enterprises.

As we have seen, almost all (94\%) manifestations of inadequate enterprise performance are the inevitable results of how enterprises are arranged (Deming, 1986); the underlying causes are 'common causes'. Only a limited percentage $(6 \%)$ of inadequate enterprise performance manifestation is attributable to erroneous actions of employees ('special causes'). Put differently, poor quality of service, alienated customers and employees, inefficiency, low productivity, waste of human, natural or financial resources, burnouts, financial crises, or failing disaster recovery (to name but a few), are all mostly the inevitable consequences of bad enterprise design. Yet, within the (Taylorist) planning and control mindset of managers, virtually only attention is paid to 'special causes', leading to even more employee control with no, or detrimental effects. All too often, this mindset is combined with a relentless focus on short-term financial gain.

In view of the enormous impact that enterprises have on individual and societal well being, we contend that enterprises have a moral obligation to avoid undesired enterprise outcomes and secure desired ones. Since, in line with Deming's observation, these outcomes are the inevitable consequences of how enterprises are arranged, achieving 
enterprise outcomes is thus first and foremost a matter of adequate and intentional enterprise design. Consequently, proper attention to enterprise design also has moral connotations. To our knowledge, enterprise engineering, as proposed and discussed in this article, is the only effective approach to formally operationalise the moral responsibilities that enterprises face. As argued, it is precisely here that serious rethinking is desperately needed. In a century after Taylor, scientific thinking about enterprises has progressed significantly. Nonetheless, enterprises continue to operate according to a century-old mindset. Hence, there is a large chasm between what science knows and what enterprises do. It is the ambition of the discipline of enterprise engineering to further increase that knowledge and to make it practically useable. This could initially aggravate the chasm. Therefore, top-management's comprehension about the importance of enterprise engineering is crucial.

The discipline of enterprise engineering that we have presented and discussed is based on a sound theoretical foundation, and is able to address enterprises holistically in all their aspects. Its practical success will significantly depend on the degree to which enterprise engineering is able to incorporate insights from the traditional organisational sciences within the design perspective. Moreover, a new and effective integration is needed of the construction perspective on enterprises, i.e., their organisations (as addressed in this article), and the function perspective, i.e., their businesses.

As it holds for all engineering disciplines (mechanical engineering, aeronautical engineering, electrical engineering, etc.), enterprise engineering will only become a serious and successful discipline if it keeps being based on sound theoretical foundations. The theories and fundamentals as presented in this paper seem to be sound, but their real value has to be assessed in evaluation and adoption studies.

\section{References}

Albani, A. and Terlouw, L. (2010) 'An enterprise ontology-based approach to service specification', IEEE Transactions on Services Computing, Vol. 6, No. 1, pp.89-101.

Alexander, C. (1960) Notes on the Synthesis of Form, Ablex Publishing Company, NJ, USA.

Argyris, C. and Schön, D. (1978) Organizational Learning, Addison-Wesley, Reading, MA.

Austin, J.L. (1962) How to Do Things with Words, Harvard University Press, Cambridge, MA.

Aveiro, D., Silva, A.R. and Tribolet, J. (2010) 'Extending the design and engineering methodology for organizations with the generation operationalization and discontinuation organization', in Winter, R., Zhao, J.L. and Aier, S. (Eds.): Proceedings of the 5th International Conference on Design Science Research in Information Systems and Technology, DESRIST 2010, 4-5 June 2010, St. Gallen, Switzerland, LNCS 6105, Springer-Verlag Berlin Heidelberg, pp.226-241.

Aveiro, D., Silva, A.R. and Tribolet, J. (2011) 'Control organization: a DEMO based specification and extension', in Albani, A., Dietz, J.L.G. and Verelst, J. (Eds.): Advances in Enterprise Engineering V. LNBIP, Vol. 79, pp.16-30, Springer, Heidelberg.

Axelrod, R. and Cohen, M.D. (2001) Harnessing Complexity, Basic Books, New York.

Beer, M., Eisenbach, R.A. and Spector, B. (1990) 'Why change programs don't produce change', Harvard Business Review, Vol. 68, No. 6, pp.158-166.

Bennis, W.G. (1989) On Becoming a Leader, Addison-Wesley, Reading, MA.

Bryan, L.L. and Joyce, C.I. (2007) 'Better strategy through organizational design', McKinsey Quarterly, No. 2, pp.21-29.

Bunge, M.A. (1977) Treatise on Basic Philosophy, Vol. 3, The Furniture of the World, D. Reidel Publishing Company, Dordrecht, The Netherlands. 
Bunge, M.A. (1979) Treatise on Basic Philosophy, Vol. 4, A World of Systems, D. Reidel Publishing Company, Dordrecht, The Netherlands.

Burns, J.M. (1979) Leadership, Harper, New York.

Butler, M. (2005) 'Measuring the value of IT', Information Economics Journal, March, pp.7-9.

Checkland, P.B. (1981) Systems Thinking - Systems Practice, John Wiley \& Sons Ltd., Chichester.

Chmielewicz, K. (1994) Forschungskonseptionen der Wirtschafswissenschaften, Pöschel, Stuttgart.

Daft, R.L. (2001) Organization Theory and Design, South-Western Publishing, Mason.

Deming, W.E. (1986) Out of the Crisis, Cambridge University Press, Cambridge.

Dietz, J.L.G. (2005a) 'A world ontology specification language', in Meersman, R. and Tari, Z. (Eds.): Proceedings OTM 2005 Workshops, Springer LNCS 3762, pp.688-699.

Dietz, J.L.G. (2005b) 'System ontology and its role in system development', in Castro, J. and Teniente, E. (Eds.): Proc. of the CAiSE'05 Workshops, University of Porto, pp.273-284.

Dietz, J.L.G. (2006) Enterprise Ontology, Springer, Berlin.

Dietz, J.L.G. (2008) Architecture: Building Strategy into Design, SDU Publishing, The Hague.

Dietz, J.L.G. and Hoogervorst, J.A.P. (2011) 'A critical investigation of TOGAF', Advances in Enterprise Engineering $V$, LNBIP 79, Springer-Verlag, Heidelberg.

Dietz, J.L.G. and van Hee, K.M. (1988) 'A framework for the conceptual modelling of discrete dynamic systems', in Rolland, C., Bodart, F. and Leonard, M. (Eds.): Temporal Aspects in Information Systems, pp.61-76, North-Holland Publishing, Amsterdam.

Dijkstra, E.W. (1976) A Discipline of Programming, Prentice-Hall Series in Automatic Computation, New Jersey.

Doz, Y. and Thanheiser, H. (1993) 'Regaining competitiveness: a process of organizational renewal', in Hendry, J., Johnson, G. and Newton, J. (Eds.): Strategic Thinking: Leadership and the Management of Change, Wiley, Chichester.

Drucker, P. (1985) Management, Harper, New York.

Drucker, P. (1991) 'The new productivity challenge', Harvard Business Review, Vol. 69, No. 6, pp.69-79.

Drucker, P. (1992) 'The new society of organizations', Harvard Business Review, Vol. 70, No. 5, pp.95-104.

Drucker, P. (1993) The Post-Capitalist Society, Harper Business, New York.

Fayol, H. (1990) 'General principles of management', in Pugh, D.S. (Ed.): Organization Theory, Penguin Books, London.

Foroohar, R. (2011) 'Driven of the road by MBA's', Time, 18 July.

Fromm, E. (1942) The Fear of Freedom, Routledge and Kegan Paul, London.

Fromm, E. (1955) The Sane Society, Rinehart and Company, New York.

Greefhorst, D. and Proper, H.A. (2011) Architecture Principles - The Cornerstones of Enterprise Architecture, Springer-Verlag, Berlin, Heidelberg.

Habermas, J. (1984) The Theory of Communicative Action: Reason and Rationalization of Society, Polity Press, Cambridge.

Hevner, A.R. (2007) 'A three cycle view of design science research', Scandinavian Journal of Information Systems, Vol. 19, No. 2, pp.87-92.

Hevner, A.R., March, S.T. and Park, J. (2004) 'Design science in information system research', MIS Quarterly, Vol. 28, No. 1, pp.75-105.

Hoogervorst, J.A.P. (1998) Quality and Customer Oriented Behavior: Towards a Coherent Approach for Improvement, Eburon, Delft.

Hoogervorst, J.A.P. (2009) Enterprise Governance and Enterprise Engineering, Springer, Berlin.

Hoogervorst, J.A.P. (2011) 'A framework for enterprise engineering', International Journal of Internet and Enterprise Management, Vol. 7, No. 1, pp.5-40. 
Hopcroft, J.E. and Ullman, J.D. (1979) Introduction to Automata Theory, Languages, and Computation, Addison-Wesley, Reading, Massachusetts.

Hounshell, D. (1984) From the American System to Mass Production, 1800-1932, John Hopkins University Press, Baltimore.

IT Governance Institute (2003) Board Briefing on IT Governance, Rolling Meadows.

Kaplan, R.S. and Norton, D.P. (2004) Strategy Maps, Harvard Business School Press, Boston.

Katz, D. and Kahn, R.L. (1978) The Social Psychology of Organizations, Wiley, New York.

Kaufman, R.S. (1992) 'Why operations improvement programs fail: four managerial contradictions', Sloan Management Review, Vol. 34, No. 1, pp.83-93.

Keller, S. and Price, C. (2011) Beyond Performance, Wiley, Hoboken.

Kim, D.H. (1993) 'The link between individual and organizational learning', Sloan Management Review, Vol. 35, No. 1, pp.37-50.

Kotter, J.P. (1988) The Leadership Factor, Free Press, New York.

Kotter, J.P. (1996) Leading Change, Harvard Business Review Press, Boston.

Langefors, B. (1977) 'Information system theory', Information Systems, Vol. 2, No. 4, pp.207-219.

Lawrence, P. and Lorsch, J. (1967) Organization and Environment, Harvard Business School Press, Boston.

Lehman, M. (1980) 'Programs, life cycles, and laws of software evolution', Proceedings of the IEEE, Vol. 68, No. 9, pp.1060-1076.

Leinwand, P. and Mainardi, C. (2010) 'The coherence premium', Harvard Business Review, Vol. 88, No. 6, pp.86-92.

Likert, R. (1965) New Patterns of Management, McGraw-Hill, New York.

Liles, D.H., Johnson, M.E. and Meade, L. (1995) 'The enterprise engineering discipline', Proceedings of the Society for Enterprise Engineering, Orlando.

Luthans, F. (1977) Organizational Behavior, McGraw-Hill, New York.

Lutz, B. (2011) Car Guys vs. Bean Counters: The Battle for the Soul of American Business, Penguin, New York.

Maizlish, B. and Handler, R. (2005) IT Portfolio Management Step-by-Step, Wiley, Hoboken.

Mannaert, H. and Verelst, J. (2009) Normalized Systems, Re-creating Information Technology Based on Laws for Software Evolvability, Kermt, Koppa.

March, S.T. and Smith, G.F. (1955) 'Design and natural science research on information technology', Decision Support Systems, Vol. 15, pp.251-266.

Martin, J. (1995) The Great Transition. Using the Seven Principles of Enterprise Engineering to Align People, Technology and, Strategy, American Management Association, New York.

Mayo, E. (1949) The Social Problems of an Industrial Civilization, Routledge and Kegan Paul, London.

McGregor, D.M. (1960) The Human Side of Enterprise, McGraw-Hill, New York.

McIlroy, M.D. (1968) 'Mass produced software components', in Naur, P. and Randell, B. (Eds.): NATO Conference on Software Engineering, 7-11 October 1968, Garmisch, Germany, Scientific Affairs Division NATO, Brussels, pp.138-155.

Miles, R.E. and Snow, C.C. (1984) 'Fit, failure and the hall of fame', California Management Review, Vol. 26, No. 3, pp.128-145.

Miles, R.E., Coleman, H.J. and Douglas Creed, W.E. (1995) 'Keys to success in corporate redesign', California Management Review, Vol. 37, No. 3, pp.128-145.

Mintzberg, H. (1989) Mintzberg on Management, Free Press, New York.

Mintzberg, H. (1994) The Rise and Fall of Strategic Planning, The Free Press, New York.

Morris, C.W. (1938) 'Foundation of the theory of signs', International Encyclopedia of Unified Science, Vol. 1, No. 2. 
Nadler, D.A. and Tushman, M.L. (1997) Competing by Design: The Power of Organizational Architecture, Oxford University Press, New York.

Nonaka, I. and Takeuchi, H. (1995) The Knowledge Creating Company, Oxford University Press, New York.

Osterman, P. (1996) Broken Ladders: Managerial Careers in the New Economy, Oxford University Press, New York.

Peirce, C.S. (1958) Collected Papers of Charles Sanders Peirce, Cambridge, Massachusetts.

Pettigrew, A. (1998) 'Success and failure in corporate transformation initiatives', in Galliers, R.D. and Baets, W.R.J. (Eds.): Information Technology and Organizational Transformation, Wiley, Chichester.

Robbins, S.P. (1990) Organization Theory, Prentice-Hall, Englewood Cliffs.

Sage, A.P. (1992) Systems Engineering, Wiley, Hoboken.

Searle, J.R. (1969) Speech Acts, an Essay in the Philosophy of Language, Cambridge University Press, Cambridge, MA.

Simon, H.A. (1969) The Sciences of the Artificial, MIT Press, Cambridge.

Simons, P. (1987) Parts - A Study in Ontology, Clarendon Press, Oxford.

Smircich, L. and Morgan, G. (1982) 'Leadership: the management of meaning', Journal of Applied Behavioral Science, Vol. 18, No. 3,pp.257-273.

Sowa, J.F. (2000) Knowledge Representation - Logical, Philosophical, and Computational Foundations, Brooks/Cole, Pacific Grove.

Stevens, R., Brook, P., Jackson, K. and Stuart, A. (1998) Systems Engineering: Coping with Complexity, Prentice Hall, Upper Saddle River.

Taylor, F.W. (1911) The Principles of Scientific Management, Harper Brothers, NY.

Taylor, J.R. and van Every, E.J. (2000) The Emergent Organization - Communications as its Site and Surface, Lawrence Erlbaum Associates Inc., New Jersey.

Trist, E.A. and Bamforth, K.W. (1951) 'Some social and psychological consequences of the Longwall method of coal-getting', Human Relations, Vol. 4, No. 1, pp.3-38.

Tsoukas, H. (1994) 'Refining common sense: types of knowledge in management studies', Journal of Management Studies, Vol. 31, No. 6, pp.761-780.

van Hee, K.M., Houben, G-J. and Dietz, J.L.G. (1989) 'Modeling of discrete dynamic systems framework and examples', Information Systems, Vol. 14, No. 4, pp.277-289.

van Kervel, S.J.H., Dietz, J.L.G., Hintzen, J., van Meeuwen, T. and Zijlstra, B. (2012) 'Enterprise ontology driven software engineering,, Proceedings of ICsoft 2012 - 7th International Conference on Software Paradigm Trends, SciTePress.

von Bertalanffy, L. (1969) General Systems Theory, George Braziller, New York.

Weaver, W. (1967) Science and Imagination, Selected Papers of Warren Weaver, Basic Books, New York.

Weber, M. (1924) 'Legitimate authority and bureaucracy', in Pugh, D.S. (Ed.) (1990): Organization Theory, Penguin Books, London.

Weick, K.E. (2001) Making Sense of the Organization, Blackwell Publishing, Oxford.

Weinberg, G.M. (2001) An Introduction to General Systems Thinking, Dorset House Publishing, New York.

Winograd, T. and Flores, F. (1987) Understanding Computers and Cognition: A New Foundation for Design, Addison-Wesley, Boston.

Witteloostuijn, A. (1999) De Anorexiastrategie, De Arbeiderspers, Amsterdam.

Wittgenstein, L. (1922) Tractatus logico-philosophicus (German text with English translation by Ogden, C.K.), Routledge \& Kegan Paul Ltd, London.

Yukl, G. (2002) Leadership in Organizations, Prentice-Hall, Englewood Cliffs.

Zuboff, S. and Maxmin, J. (2002) The Support Economy, Penguin Press, London. 


\section{Notes}

1 Antonia Albani, University of St. Gallen, antonia.albani@unisg.ch

David Aveiro, University of Madeira; CODE, INESC INOV, Lisbon, daveiro@uma.pt

Eduard Babkin, Higher School of Economics at Nizhny Novgorod, eababkin@hse.ru

Joseph Barjis, Delft University of Technology, J.Barjis@tudelft.nl

Artur Caetano, TU Lisboa, IST, INESC, Lisbon, artur.caetano@ist.utl.pt

Philip Huysmans, University of Antwerp, Philip.Huysmans@ua.ac.be

Junichi Iijima, Tokyo Institute of Technology, iijima.j.aa@m.titech.ac.jp

Steven van Kervel, Formetis, Netherlands, steefk22@telenet.be

Hans Mulder, Antwerp Management School, hans.mulder@ua.ac.be

Martin Op 't Land, Capgemini, Antwerp Management School,

Delft University of Technology, martin.optland@capgemini.com

Henderik A. Proper, CRP Henri Tudor; Radboud Uni Nijmegen, erik.proper@tudor.lu

Jorge Sanz, IBM Research, Almaden CA, USA, jorges@us.ibm.com

Linda Terlouw, ICRIS, The Netherlands, linda.terlouw@icris.nl

José Tribolet, TU Lisboa, IST, INESC, Lisbon, Jose.Tribolet@inesc.pt

Jan Verelst, University of Antwerp, jan.verelst@ua.ac.be

Robert Winter, University of St. Gallen, robert.winter@unisg.ch

2 With 'enterprise' we refer to all kinds of organised activity (like companies, governmental agencies, healthcare institutions, and supply chains).

3 In the traditional organisational sciences this notion is commonly referred to as 'organisational learning'.

4 Cf. http://www.iseenet.org.

5 The original meaning of the Greek word 'ontology' is: knowing how things are.

6 The original meaning of the Greek word 'technology' is: knowing how to make things.

7 Although we regularly refer to literature sources where theories are discussed, they are not always referred to by the Greek-letter-name in these sources.

8 Note that the term 'engineering' is used here in the narrow sense, unlike its meaning in 'mechanical engineering', 'aeronautical engineering', 'enterprise engineering', etc.

9 DEMO is an acronym for design and engineering methodology for organisations. It is a pioneering methodology in enterprise engineering (http://www.ee-institute.com). 